\title{
An observational cross-sectional study to assess knowledge, attitude and practice of resident doctors and nursing professionals regarding pharmacovigilance in a tertiary care teaching hospital in Central India
}

\author{
Akash Vishwe*, Satish Chandel, Ratinder Jhaj, Santenna Chenchulla, Niket Rai
}

\begin{abstract}
Department of Pharmacology, AIIMS, Bhopal, Madhya Pradesh, India

Received: 13 March 2017 Accepted: 06 April 2017

*Correspondence to: Dr. Akash Vishwe, Email: draksh.vishwe@ gmail.com
\end{abstract}

Copyright: (C) the author(s), publisher and licensee Medip Academy. This is an openaccess article distributed under the terms of the Creative Commons Attribution NonCommercial License, which permits unrestricted noncommercial use, distribution, and reproduction in any medium, provided the original work is properly cited.

\begin{abstract}
Background: Adequate knowledge, positive attitude and motivated practice of pharmacovigilance are the building pillars of ADR reporting. This study was conducted to evaluate the knowledge and attitude towards pharmacovigilance and adverse drug reaction reporting among the resident doctors and nursing staff in AIIMS Bhopal, Madhya Pradesh, India.

Methods: This cross-sectional questionnaire based study was carried out in a tertiary care centre. The survey was carried out using a pre-validated questionnaire that included 20 questions to evaluate the participant's knowledge, attitude and practice.

Results: Answers to knowledge based questions were given correctly by around 82.6\% (95\% CI 0.7576 to 0.8794 ) of resident doctors and 74\% (95\% CI 0.6033 to 0.8424$)$ nursing professionals. The difference of basic knowledge about pharmacovigilance between resident doctors and nursing professionals was insignificant ( $\mathrm{p}$-value is 0.7967 ). The most common reason for underreporting was unawareness, which was opted by $69 \%$ (95\% CI $0.6153-0.7617)$ of resident doctors, while among the 58\% (95\% CI 0.4422-0.7064) nursing staff, the major factor was non-feasible ADR monitoring system in hospital. The suggestion of conducting training and awareness programme to promote ADR reporting given by resident doctors and nursing staff were $85 \%$ (95\% CI $0.7872-0.0957$ ) and $80 \%$ (95\% CI 0.6677-0.8895) respectively.

Conclusions: The participants were well aware of pharmacovigilance and adverse drug reaction reporting. They had expressed the positive attitude towards pharmacovigilance and ADR reporting. But the routine practice of reporting ADRs is lacking. Hence there is need for increasing awareness and building positive attitude and practices among the health care professionals.
\end{abstract}

Keywords: Attitude and practice, Knowledge, Nursing professionals, Pharmacovigilance, Resident doctors

\section{INTRODUCTION}

Despite the importance of drugs in the prevention and treatment of diseases, their usage is sometimes associated with undesirable adverse reactions. Safe use of drug is an important aspect of practice of medicine. Reducing the incidence and consequences associated with adverse drug reactions is a crucial challenge. Adverse drug reactions (ADRs) are associated with a significant morbidity, mortality and increase in treatment cost. ${ }^{1}$ According to World Health Organization definition, an ADR is any noxious, unintended, and undesired effect of a drug, which occurs at the doses which are used in humans for prophylaxis, diagnosis, or treatment. ${ }^{2}$

According to Jacoline et al., the median percentage of patients who experienced adverse drug reaction during hospitalization was $10.1 \%{ }^{3}$ A metanlysis by Lazarou et al showed that the overall incidence of serious ADRs in USA was $6.7 \%$, of which incidence of fatal ADRs were $0.32 \% .^{4}$ Ramesh et al observed that $0.7 \%$ of hospital admissions in South India were due to ADRs and a total of $3.7 \%$ of the hospitalized patients experienced an ADR, out of which $1.3 \%$ were found to be fatal. ${ }^{5}$ Some meta- 
analysis and studies have revealed that an adverse drug reaction is the fourth to sixth leading cause of death in USA. $^{4,6}$ Mortality can be reduced by effective pharmacovigilance as many of the ADRs are preventable. $^{7}$

Spontaneous adverse drug reaction (ADRs) reporting system is considered the back-bone for any pharmacovigilance system. Within this context, active involvement of healthcare professionals is very crucial to improve the rate and quality of ADRs reporting. Despite the various techniques that have been adopted in order to improve the rate and quality of ADR reporting, underreporting of ADRs is a well-recognized global phenomenon. ${ }^{9}$ It is estimated that only $6-10 \%$ of adverse drug reactions are reported. ${ }^{8}$

India became the member of WHO programme for international drug monitoring managed by Uppsala monitoring centre (UMC), Sweden. In the beginning 6 centers were established. In 2004 government of India initiated National Pharmacovigilance Programme with aid from World Bank; unfortunately, the programme was temporarily suspended in 2009. Recognizing the importance of ADR monitoring in the country, the programme was relaunched as Pharmacovigilance programme of India, in July 2010. Initially, national coordinating center was All India Institute of Medical Sciences, New Delhi; then in next year it was shifted to India Pharmacopeia Commission, Gaziabad.

In this programme, ADRs are being indentified and spontaneously reported through ADR monitoring centers. Initially there were $22 \mathrm{AMCs}$, then its number increased to 150 in 2015 and in near future it is planned to increase AMCs over 350 across the nation

In our institute, AMC was established in January 2014 under coordinator ship of Dr. Ratinder Jhaj. More than 450 ADRs have been reported through our center. We received ADRs from all departments but the maximum contribution was from dermatology.

Resident doctors and nurses work in close contact with the patients. Studies from different settings indicate inadequate knowledge about pharmacovigilance and lack of reporting among healthcare professionals as well as attitudes that are associated with a high degree of underreporting. Hence the present study was undertaken to evaluate the knowledge and attitude about pharmacovigilance among resident doctors and nursing staff. Moreover, the opinions and suggestions opted by participants were also discussed.

\section{METHODS}

Design of this study was a questionnaire-based crosssectional and observational study conducted in All India Institute of Medical Sciences Bhopal during the period of June 2015 to May 2016. The questionnaire was structured to observe and assess the knowledge, attitudes and practice of doctors and health care professionals toward reporting ADRs. The questionnaire consisted of three sections of knowledge (8 questions), attitude (7 questions) and practice (5 questions).

The questions were structured. The language of the questionnaire was English as all health care professionals know English, moreover in case of any technical difficulty an investigator help was provided. Knowledge based questions have multiple choice, participants were supposed to answer the correct option. In the questions to assess attitude, participants are allowed to answer multiple options as per their opinion. And in case of practice based questions participants are supposed to choose option in accordance to their practice in Pharmacovigilance.

All the resident doctors and nursing professionals willing to take part in the study were included in study. Total 200 health care professionals participated in the study; out of them 150 were resident doctors while rests of them were nursing professionals. One of the investigators approached every participant and requested them to participate in the study and answer the questionnaire as early as possible. The participants who are correct for four questions out of 8 were found to have adequate knowledge. An attempt was also made to find out various factors that may influence ADR reporting. It was a closed-end questionnaire.

\section{Data collection}

The investigating team personally approached resident doctors and health care professionals and invited them to participate in the study. Suggestions were also invited for possible ways to improve ADR reporting. Participants could complete the questionnaire and hand it back immediately, or return the duly filled questionnaire within a week.

\section{Statistical analysis}

Data was analyzed and calculated with $95 \%$ confidence interval. Responses of resident doctors and nursing staff were compared using the chi-square test. The p-value of 0.05 was considered significant.

\section{RESULTS}

A total of 200 health care professionals participated in the study, out of which 150 were resident doctors and 50 were nursing professionals. Among the resident doctors, around $82.6 \%$ (95\% CI 0.7576 to 0.8794$)$, while $74 \%$ of nursing staff (95\% CI 0.6033 to 0.8424$)$ had adequate knowledge about pharmacovigilance. There was no significant difference between resident doctors and nursing professionals in view of basic knowledge about Pharmacovigilance ( $\mathrm{p}$-value is 0.1804). 
The major factors responsible for under-reporting of adverse drug reactions cited by $69 \%$ ( 0.6153 to 0.7617$)$ of resident doctors was lack of awareness about how to report an ADR, while among the nursing staff 58\%
(0.4422 to 0.7064) opted for non-feasible ADR monitoring system in hospital. The other factors hindering the ADR reporting are given in Table 1. Significantly higher number of resident doctors felt that lack of awareness and lack of time are factors leading to underreporting of ADRs (Table 1).

Table 1: The factors responsible for under-reporting of adverse drug reactions.

\begin{tabular}{|llll|}
\hline Factors & $\begin{array}{l}\text { \% of residents } \\
(\mathbf{n = 1 5 0}) \text { and 95\% CI }\end{array}$ & $\begin{array}{l}\text { \% of nursing staff } \\
(\mathbf{n = 5 0} \text { and 95\% CI }\end{array}$ & \begin{tabular}{l} 
P- value \\
\hline Lack of an ADR monitoring system in hospital
\end{tabular} \\
\hline Lack of awareness about how to report ADR & $61 \%(0.5267-0.6813)$ & $58 \%(0.4422-0.7064)$ & 0.7074 \\
\hline Lack of time to fill an ADR form & $69 \%(0.6153-0.7617)$ & $40 \%(0.2759-0.5384)$ & 0.0003 \\
\hline Concern that reporter may be blamed for ADR & $35 \%(0.2813-0.4327)$ & $18 \%(0.0954-0.3102)$ & 0.0241 \\
\hline Lack of confidence when an unknown ADR is encountered & $33 \%(0.1725-0.3075)$ & $18 \%(0.0954-0.3102)$ & 0.458 \\
\hline Inability to diagnose ADR & $16 \%(0.1093-0.2276)$ & $6 \%(0.0144-0.1684)$ & 0.0731 \\
\hline Laziness & $22 \%(0.1608-0.2932)$ & $8 \%(0.0264-0.1935)$ & 0.0273 \\
\hline Fear of legal action & $26 \%(0.1962-0.3358)$ & $18 \%(0.0954-0.3102)$ & 0.2513 \\
\hline
\end{tabular}

Table 2: Attitudes of resident doctors and nursing staff regarding pharmacovigilance.

\begin{tabular}{|c|c|c|c|}
\hline Factors & $\begin{array}{l}\% \text { Resident doctors } \\
(\mathrm{n}=150) \text { and }(95 \% \mathrm{CI})\end{array}$ & $\begin{array}{l}\% \text { Nursing staff } \\
(\mathrm{n}=50) \text { and }(95 \% \mathrm{CI})\end{array}$ & P-value \\
\hline ADR reporting is necessary & $95 \%(0.9051-0.9789)$ & $90 \%(0.7821-0.9609)$ & 0.2059 \\
\hline Expect feedback from ADR monitoring center & $87 \%(0.7821-0.9609)$ & $92 \%(0.8065-0.9736)$ & 0.3417 \\
\hline ADR reporting may damage their professional image & $8 \%(0.0452-0.1358)$ & $18 \%(0.0954-0.3102)$ & 0.458 \\
\hline $\begin{array}{l}\text { ADR reporting is time consuming activity without any } \\
\text { outcome }\end{array}$ & $6 \%(0.0304-0.1116)$ & $20 \%(0.1105-0.3323)$ & 0.0035 \\
\hline There should be direct ADR reporting by the patient & $55 \%(0.4734-0.6306)$ & $80 \%(0.6677-0.8895)$ & 0.0017 \\
\hline
\end{tabular}

Nintey five percent of resident doctors and $90 \%$ of nursing staff felt that ADR reporting is necessary. Most of resident doctors $(87 \%)$ and nursing staffs $(92 \%)$ expect feedback from ADR monitoring center. Only a small percentage of health care workers thought that ADR reporting may damage their professional image. Some of the resident doctors $(6 \%)$ and the nursing staff $(20 \%)$ opined that ADR reporting is a time-consuming activity without any beneficial outcome. Around half of resident doctors and a majority of nursing staff felt that there should be direct ADR reporting by the patient (Table 2).

Around 59\% (95\% CI 0.5133-0.6687) of resident doctors and $66 \%(95 \%$ CI $0.5211-0.7761)$ of nursing staff responded that they came across ADRs in their routine practices, the difference among them is statistically insignificant ( $\mathrm{p}$-value 0.38 ). Thirty-one per cent $(95 \% \mathrm{CI}$ $0.2444-0.3916)$ of resident doctors and $28 \%$ (95\% CI 0.1738-0.4176) of nursing staff had reported ADRs; difference being statistically insignificant ( $p$-value $0.6892)$.

Thirty seven percent $(0.2999-0.4531)$ of resident doctors said they never came across any ADR in their routine practice and $15 \%$ (95\% CI $0.1038-0.2202)$ of them did not know that they are supposed to report an ADR, $8 \%$ (95\% CI 0.0452-0.1358) of resident doctors were unable to diagnose the ADR. Among the nursing staff, while 5\% (95\% CI 0.0144-0.1684) had never come across an ADR, all of them knew that they are supposed to report an ADR, $8 \%$ (95\% CI 0.0264 to 0.1935$)$ of nursing staff were unable to diagnose it. ADR observing practices of resident doctors and nursing staff differ significantly ( $p$ value of 0.0001 ) while practice of inability to diagnose an ADR does not differ significantly ( $p$ value of 0.999 ).

Approximately $28 \%$ (95\% CI $0.2141-0.3569)$ of resident doctors and $24 \%$ (95\% CI 0.1416-0.3755) nursing staff said that they have reported an ADR to AMC in their current work place. The reporting rate of resident doctors and nursing staff did not differ significantly ( $\mathrm{p}$ value $0.5811)$. Forty-four per cent (95\% CI $0.3630-0.5200)$ of resident doctors and 38\% (95\% CI $0.2584-0.5188$ ) of nursing staff had seen ADR reporting form, statistically the difference is not significant ( $p$ value 0.4573 ).

Around $85 \%$ (95\% CI 0.7872-0.0957) resident doctors felt that ADR reporting should/can be increased by training and awareness programme, $23 \%$ (95\% CI 0.1725 0.3075 ) thought that it should be made compulsory by medicolegal law while $39 \%$ (95\% CI $0.3187-0.4733)$ of resident doctors agree with interdepartmental cooperation. Similarly, $80 \%$ (95\% CI 0.6677-0.8895) of nursing staff said ADR reporting can be improved 
through training and awareness programme, while $28 \%$ (95\% CI $0.1738-0.4176)$ and $26 \%$ (95\% CI $0.1576-$ $0.3967)$ of participants agreed with compulsion by medicolegal law and interdepartmental co-operation respectively. All these suggestions given by resident doctors and nursing staff do not differ significantly with $\mathrm{p}$ value of (0.4066), (0.475) and (0.0967) respectively.

\section{DISCUSSION}

Present study revealed moderate awareness about the ADR reporting system among the resident doctors and nursing professionals. This was not in agreement with the results of Hardeep et al and Li Qing et al. ${ }^{10,11}$ Sixtey nine percent resident doctors and $40 \%$ nursing professionals did not know where and how the ADRs had to be reported. Therefore, it seems necessary to hold awareness programme to improve the ADR reporting and encourage nursing professionals to report ADRs, since they are in close contact with the patients for a longer duration. And hence they can play an important role in making the pharmacovigilance programme more successful.

This study revealed that the major factor responsible for under-reporting of adverse drug reactions is lack of knowledge about how and where to report. This result was in accordance to study conducted by Hardeep et $\mathrm{al}^{10}$ A study conducted in Sweden by Ekman E has revealed that the most common reason for refraining from reporting was that the adverse reactions were well known. ${ }^{12}$ Another study conducted by Bateman et al., revealed that the amount of time taken to report an ADR is the major determinant for low ADR reporting while other factors are lack of appreciation of ADR reporting, complexity of the ADR reporting process and the belief that it was not their responsibility to report ADR. ${ }^{13}$ Uncertainty regarding the causal relationship between the event and the suspected drug is also a barrier for ADR reporting by Vallono et al. ${ }^{14}$

Around $95 \%$ of resident doctors and $90 \%$ of nursing staff think that ADR reporting is necessary, which again coincide with the results obtained by Li Qing et al. ${ }^{11}$ But not with those which were obtained by Bateman et al. ${ }^{13}$ Moreover, large proportion of health care workers expect feedback from ADR monitoring center. Some of the resident doctors and nursing staff think that ADR reporting may damage their professional image, while others agree that ADR reporting is a time-consuming activity without any outcome. A good number of resident doctors $(55 \%)$ and nursing staff $(80 \%)$ think that there should be direct ADR reporting by the patients. Study conducted by Oshikoya et al, revealed that $64 \%$ of respondent felt that ADR reporting is a professional obligation, about half $52 \%$ of them think that ADR reporting should be compulsory while $36 \%$ respondents opted that it should be voluntary. ${ }^{15}$ In a study conducted by Pimpalkhute et al, regarding the general attitude of participants towards ADR reporting revealed that $15.19 \%$ respondents said that it should be made compulsory,
$41.66 \%$ said it should be voluntary and $3.57 \%$ said it should be remunerated. $21.42 \%$ of respondents felt that identity of prescriber should be concealed while $29.7 \%$ respondents felt that identity of reporter should be concealed. ${ }^{16}$

We found that only a quarter of health care workers had reported an adverse drug reaction in past. This result was in accordance with Qing $L$ et al. ${ }^{11}$ Another study conducted in India by Desai et al, had shown that, only $15 \%$ of the prescribers had reported ADRs previously and the reasons behind the low reporting were lack of information on where $(70 \%)$ and how $(68 \%)$ to report and the lack of access to reporting forms was reasoned by $49.2 \% .^{1}$ Pimpalkhute et al, have found that $67.85 \%$ of respondents observed an ADR but only $25 \%$ reported in spite of the fact that $44.04 \%$ were aware about the complete procedure of ADR reporting. ${ }^{16}$

To improve the spontaneity in the reporting rates, the participants had suggested the organization of training and awareness programmes, and interdepartmental cooperation. Various other similar studies which were conducted by Jha et al, Tabali et al and Figuieras et al, demonstrated that an educational intervention could increase the physician's awareness about pharmacovigilance and ADR reporting. ${ }^{17-19}$ As a result of which the physicians would be able to incorporate the knowledge that they gained from their training into their everyday clinical practice. The limitation of present study are its single centric design and observational type. In order to strengthen and generalize our findings, it is imperative that similar studies should be conducted in other teaching hospitals of the country.

\section{CONCLUSION}

Health care workers have adequate knowledge and positive attitude about pharmacovigilance but the practice of reporting ADR is lacking. Present study strongly suggested that there is a need to create positive attitude and to increase awareness among the doctors and other health care workers to improve the reporting of ADRs. Training sessions and awareness programme must be conducted at regular intervals. There should be a feedback from ADR monitoring center to the reporter. ADR reporting should be made an essential part of the clinical practice in order to improve the patient's safety.

Funding: By Department of Pharmacology AIIMS, Bhopal, Madhya Pradesh, India

Conflict of interest: None declared

Ethical approval: The study was approved by the Institutional Ethics Committee AIIMS Bhopal with registration number of IHEC-LOP/2015/IM005I

\section{REFERENCES}

1. Desai CK, Iyer G, Panchal J, Shah S, Dikshit RK. An evaluation of knowledge, attitude, and practice of 
adverse drug reaction reporting among prescribers at a tertiary care hospital. Perspect Clin Res. 2011;2:129-36.

2. World Health Organization. Safety of medicines. A guide to detecting and reporting adverse drug reactions. Geneva, Switzerland: World Health Organization; 2002.

3. Bouvy JC, De Bruin ML, Koopmanschap MA. Epidemiology of adverse drug reactions in Europe: a review of recent observational studies. Drug Saf. 2015;38:437-53.

4. Lazarou J, Pomeranz BH, Corey PN. Incidence of adverse drug reactions in hospitalized patients. A meta-analysis of prospective studies. JAMA. 1998;279:1200-5.

5. Ramesh M, Pandit J, Parthasarathi G. Adverse drug reactions in a south Indian hospital-their severity and cost involved. Pharmacoepidemiol Drug Saf. 2003; 12:687-92.

6. Classen DC, Pestotnik SL, Evans RS, Lloyd JF, Burke JP. Adverse drug events in hospitalize patients. excess length of stay, extra costs and attributed mortality. JAMA. 1997;277:301-6.

7. McDonnell PJ, Jacobs MR. Hospital admissions resulting from preventable adverse drug reactions. Ann Pharmacother. 2002:36;1331-6.

8. Feely J, Moriarty S, O'Connor P. Stimulating reporting of adverse drug reactions by using a fee. BMJ. 1990;300:22-3.

9. Lopez-Gonzalez E, Herdeiro MT, Figueiras A. Determinants of under-reporting of adverse drug reactions: a systematic review. Drug Saf. 2009;32:1931.

10. Hardeep, Bajaj JK, Kumar R. A survey on the knowledge, attitude and the practice of pharmacovigilance among the health care professionals in a teaching hospital in Northern India. J Clin Diag Res. 2013;7(1):97-9.

11. Qing L, Su-min Z, Hua-ting C, Shi-ping F, Xin Y, Dong L. The awareness and the attitudes of the healthcare professionals in China about/towards the reporting of adverse drug reactions. Chinese Med J. 2004;117(6):856-61.
12. Ekman E, Bäckström M. Attitude among hospital physicians to the reporting of adverse drug reactions in Sweden. Euro J Clin Pharmacol. 2009;65(1):43-6.

13. Bateman DN, Sanders GLS, Rawlins MD. The attitudes to the adverse drug reaction reporting in the northern region. $\mathrm{Br} \quad \mathrm{J}$ Clin Pharmacol. 1992;34(5):421-6.

14. Vallano A, Pedrós C, Agustí A, Cereza G, Danés I. Educational sessions in pharmacovigilance: What do the doctors think? BMC Res Notes. 2010;3:311.

15. Oshikoya K, Awobusuyi J. Perception of doctors to adverse drug reactions in a teaching hospital in Lagos, Nigeria. BMC Clin pharmacol. 2009;9:14.

16. Pimpalkhute SA, Jaiswal KM, Sontakke SD, Bajait CS, Gaikwad A. Evaluation of awareness about pharmacovigilance and adverse drug reaction monitoring in resident doctors of tertiary care teaching hospital. Indian J Med Sci. 2012;66:55-61.

17. Jha N, Rathore DS, Shankar PR, Gyawali S, Alshakka M, Bhandary S. An educational intervention's effect on healthcare professionals' attitudes towards pharmacovigilance. AMJ. 2014;7(12):478-89.

18. Tabali M, Jeschke E, Bockelbrink A, Witt CM, Willich SN, T, Matthes H. An educational intervention to improve the physicians' reporting of the adverse drug reactions (ADRs) in a primary care set- ting in the complementary and alternative medicine programs. BMC Public Health. 2009;9:274.

19. Figueiras A, Herdeiro MT, Polonia J, Gestal-Otero JJ. An educational intervention to improve physician reporting of adverse drug reactions: a cluster randomized controlled trial. JAMA. 2006;296:1086-93.

Cite this article as: Vishwe A, Chandel S, Jhaj R, Chenchulla S, Rai N. An observational crosssectional study to assess knowledge, attitude and practice of resident doctors and nursing professionals regarding pharmacovigilance in a tertiary care teaching hospital in Central India. Int J Basic Clin Pharmacol 2017;6:1201-5. 